\title{
Knowledge Production and Social Roles in an Online Community of Emerging Occupation: A Study of User Experience Practitioners on Reddit
}

\author{
Yubo Kou, Colin M. Gray, Austin L. Toombs, and Robin S. Adams \\ Purdue University, West Lafayette, IN 47907 \\ $\{$ kou2, gray42, toombsa, rsadams\}@purdue.edu
}

\begin{abstract}
New occupations are emerging that have high job demand in the market, but lack a coherent body of disciplinary knowledge. For example, user experience (UX) design is an emerging occupation that has not been adequately supported by the traditional educational system. For learners beginning their undergraduate education, there is no concrete path to follow to become a UX professional, due to few UXfocused undergraduate academic programs. Online communities of practices have been recognized as important learning venues, even while institutions of formal education often lag behind in structuring knowledge production and distribution. However, little is known about how knowledge is generated and diffused in online communities in the context of emerging occupations with volatile knowledge boundaries. In this paper, we analyze knowledge production in relation to social roles in an online $U X$ community. We show that knowledge production is highly distributed, involving the participation of community members of varied levels of experience. We discuss how online communities support the development of the UX occupation.
\end{abstract}

\section{Introduction}

Emerging occupations, ones that are becoming "numerically important or emerging due to technological change" [8], typically appear at the edge of the burgeoning "knowledge economy," and whose growth demands a vibrant labor force. Due to their emerging nature, these occupations often have volatile knowledge boundaries and lack a coherent body of disciplinary knowledge. This manifests in formal education (i.e., colleges and universities) falling behind in creating corresponding disciplines and teaching essential knowledge [26,39]. Numerous reports show that emerging occupations also lack a sufficient number of qualified professionals to perform necessary work
$[20,35,47]$. Therefore, it becomes critically important to understand how knowledge is produced and disseminated in the context of emerging occupations.

In recent years, online communities have been viewed as vital places that can enable learning and socialization of both amateur and professional practitioners in a wide range of disciplines [34,37,43]. However, little work has focused on the processes of knowledge production in the context of emerging occupations. For example, regarding user experience (UX) design, scholars have demonstrated how informal online social spaces may enable learning [22], but the community-level dimensions of interaction could be more thoroughly studied, including aspects of how the flow of knowledge is created and validated by community members. Thus, there are substantial opportunities to better understand how knowledge is generated, diffused, and consumed in online communities that cater to emerging occupations. In this paper, we use the term community of emerging occupation to denote a community consisting of practitioners from an emerging occupation.

In this paper, we focus on the "/r/userexperience" subreddit, an active online community where UX practitioners interact and share knowledge about their discipline through Reddit, one of the most popular online forums [1]. Initially designed as a social news site, Reddit has supported the formation, maintenance, and development of online communities of various focuses $[29,36]$, out of which the aforementioned subreddit is a rapidly growing one attracting both amateur and professional UX designers. Through Reddit's official API, we retrieved 970 posts and their 6958 associated comments that contain user experience practitioners' professional conversations on a variety of topics such as UX academic program, UX jobs, and UX software. By focusing on this particular online community, we are not denying the existence of other forms of online or offline communities focused on UX, such as university departments, professional associations, or local meetups. Rather, we seek to explore what role online communities can play in knowledge production and dissemination in the context of emerging occupations. 
Using a mixed-methods approach, we examine patterns of knowledge production and diffusion in this community. We will demonstrate that there is no core group of members governing knowledge production and distribution. Instead, members with various experiences, backgrounds, and level of participation (or "vocality," defined later) can make quality contributions to the community, which is consistent with the interdisciplinary nature of UX in absorbing knowledge from other disciplines. We use this understanding of knowledge creation and validation to further understand the roles that community members take on. Drawing from the perspective of community of practice $(\mathrm{CoP})$, we argue that this community of emerging occupation is a particular type of $\mathrm{CoP}$ within which ongoing knowledge construction takes place towards the professionalization of this occupation. This study contributes to a deeper understanding of the relationship between technological spaces and the self-learning practices of UX designers in three ways. We (1) present an empirical study that documents self-learning practices in an online community of emerging occupation; (2) discuss processes of construction of UX knowledge that may reveal pathways towards UX professionalization; and (3) theorize the relationship between professional conversations and social roles in online spaces.

\section{Related work}

\subsection{UX as an emerging occupation}

User experience (UX) design has emerged as an important field of design practice. UX represents a shift away from purely visual or product-oriented conceptions of design, towards the design of interactions and services. This shift was proposed by Buchanan [6] as a natural growth of the design profession, embodying an increasingly humanist, complex, and socially-intertwined understanding of design activity and outcomes (c.f., four "orders" of design). UX has emerged as a distinct yet overlapping discipline alongside human-computer interaction (HCI) and interaction design, reflecting the increasingly ubiquitous function of technology and technological systems in our everyday lives. Core tenets of UX claim that users' interactive experiences with technology demand careful design consideration [27]. As UX has emerged as a design discipline in its own right, this perspective on design has been viewed as a strategic advantage in knowledge-based companies [13], and its related jobs are commonly cited as an area of rapid growth [12,30].
However, the practice of UX design also introduces significant challenges to design learning and education, because there is little consensus over what can or should constitute a coherent body of UX knowledge [42]. UX is inherently interdisciplinary in nature, comprised of a variety of knowledge, theories, and methodologies from multiple disciplines such as engineering, computer science, sociology, and psychology. Few UX-focused academic programs exist at the undergraduate level in universities and colleges, and although a significant number of UX designers are trained on the graduate level, many programs at this level are more generally focused on HCI, information science, or related academic fields. Additionally, few formal means of certification and licensure agencies are consistently accepted as relevant or valid by UX practitioners. Hence, there is no direct or well-defined path to becoming a UX professional, and neither is there a definite means of maintaining and developing UX expertise and skills for existing practitioners [24].

UX is an interdisciplinary field that has absorbed ideas from multiple disciplines [14], and has been referenced as an emerging trans-discipline that creates a new fusion of human interests in relation to interaction and service (e.g., [4]). Due to the emergent and evolutionary nature of this new inter- and transdisciplinary space, ideas and opinions in the UX field are contested, often lacking even a consensus over the definition of UX. Hassenzahl and Tractinsky [27] identified three distinct perspectives towards UX, arguing that " $\mathrm{UX}$ is about technology that fulfils more than just instrumental needs in a way that acknowledges its use as a subjective, situated, complex and dynamic encounter. UX is a consequence of a user's internal state, the characteristics of the desired system and the context within which the interaction occurs." Law et al.'s survey study of UX professionals [33] reported that most respondents agreed that UX is dynamic, contextdependent, and subjective.

\subsection{Community of practice}

To understand the learning practices of UX designers, we adopt a social constructivist perspective which posits that learning is fundamentally social and situated in a context $[32,44]$. The concept of Community of Practice (CoP) that has grown out of this theoretical perspective has been highly influential in allowing researchers to interpret and analyze learning practices in online communities, which is also how we use the concept in this paper. Lave and Wenger introduced the $\mathrm{CoP}$ concept in their book Situated Learning: Legitimate Peripheral Participation [32], marking a drastic shift in understanding learning practices by arguing that formal educational settings are not the only 
place to study learning in practice. Wenger [46] later expanded the idea from a concept primarily concerned with the internal dynamics of learning in a group, to one that could describe relationships between communities through the use of boundary objects [41]. Observing the ubiquity of $\mathrm{CoP}$ and its applicability to both professional and informal, everyday aspects of our lives, Wenger [46] noted that "At home, at work, at school, in our hobbies - we belong to several communities of practice at any given time. And the communities of practice to which we belong change over the course of our lives. In fact, communities of practice are everywhere." In this regard, the CoP concept has attempted to include practically all of social life, favoring generality in describing the ubiquity of learning over precision.

An important component of the $\mathrm{CoP}$ is the divide between newcomers and old-timers. Old-timers define and diffuse knowledge to newcomers, while newcomers participate and learn through legitimate peripheral participation at the boundaries defined and watched by old-timers [32]. Newcomers assume more important roles and become more senior in the community over time. In interdisciplinary contexts that have no single or formal home, newcomers rely upon their social networks to create their own pathways to become a professional [40].

\subsection{Social roles in online communities}

Social roles can be viewed as sets of activities performed by individuals $[19,28]$. Roles are important in providing a division of labor that facilitates the functioning of the community, supplying a normative function that help establish norms and order among the community, and helping each community member build their own identity within the community [5]. Herrmann et al. suggested that better support of role mechanisms can facilitate communication, knowledge exchange, and learning in online communities [28].

Online community researchers have been interested in various means of discovering the diverse social roles that people play in shaping community structure and organizing social practices among members. Ample research has been done in exploring social roles formed based on functional roles that are defined by the design of online community platforms. For example, Wikipedia assigned users different functional roles along a hierarchy, including editors, former users, WikiProject founders, developers, and others [3,15]. These functional roles do not confine users; rather, users might form distinctive characteristics through their long-term engagement with functional roles. Wesler et al. showed that four types of social roles (technical editors, vandal fighters, substantive experts, and social networkers) evolved based on predefined functional roles in Wikipedia [45]. However, many online platforms such as online forums do not have many role types beyond moderator and average user.

One common tactic for studying these contexts uses primarily quantitative metrics of users' online behaviors and social networks to infer different social roles $[7,11,16,18,38]$. We build on this tactic by also including the participant perspective of these roles through a qualitative analysis of discourse that reflects community members' thoughts about their contributions to their community. In particular, we focus on how social roles and activities relate to community members' practices of generating and circulating knowledge.

\section{Purpose}

While previous research on online UX communities have mostly pointed to the value of technology in supporting UX self-learning and education (e.g., $[22,25])$, in this study, we investigate the relationship between knowledge production and social roles on the community level. The study addresses the following research questions:

1. How does vocality influence knowledge activity in the online community?

2. What roles do community members take on when participating?

\section{Methods}

We used mixed methods including statistical tests and qualitative content analysis to address the two research questions. We used statistical tests to measure UX practitioners' level of participation. We used qualitative content analysis to investigate types of contributions in this online community.

\subsection{Data collection}

Prior research on UX practice has suggested that UX practitioners commonly use online communities to remain competent over time [21,22]. Through long-term observation of a sample of online communities, we identified multiple communities relevant to UX on Reddit, one of the largest online forums in the world. Reddit allows data collection and analysis through an official API. We used keyword search and snowball sampling to identify subreddits (Reddit's subcommunities with a unique set of followers, posting rules, and social practices) that had a primary or secondary focus on UX. Keywords included "design," "usability," "user experience," and "user research." We identified 14 subreddits in total. After initial analysis of 
and comparison between these subreddits using descriptive statistics such as number of posts per month and number of comments per post, we found that the /r/userexperience subreddit was the most active one. In the eight months of community interactions that had taken place by the time of our data collection, the subreddit had accumulated more threads than all the other UX-related subreddits combined. Additionally, the community members showed high level of engagement in terms of the number of authors and comments. The subreddit had the largest average number of comments per post and the largest number of distinct authors. Therefore, we chose this subreddit for further investigation.

We used PHP and the Reddit API to retrieve all the post and comment data from the subreddit, and stored the data in a MySQL database for further analysis. The final dataset included 970 posts and their 6958 associated comments from January 19, 2016 to August 24, 2016. We gathered data from this particular time period because the Reddit API only allowed a maximum number of 1000 posts by the time we collected data. The metadata of each post and comment was also saved. Post metadata included the title, author, timestamp, content, shared URL (if applicable), number of comments, and score. Comment metadata included the content, author, timestamp, upvote number, and score. Connections between posts and comments were maintained through a relational key. The dataset also included 1967 distinct users who had either made a post or a comment, with 610 having made at least one post and 1743 having commented at least once. Post and comment volume was roughly consistent from month to month, with a slight rise during the last two months (July and August), indicating steady growth.

\subsection{Data analysis}

Regarding the first research question, we measure a person' vocality in the online UX community by their degree of activeness in the community, indicated by their number of posts or number of comments. We consider a post's score and number of comments as indicators of how the community receives and values the post. Posts that have higher scores and more comments suggest that the community values such threads. We also consider a comment's score as an indicator of how the community values the comment. Comments that have higher scores suggest more value as perceived by the community. In the dataset, almost all the posts and comments are associated with an author name, except for nine posts and 123 comments where the author name shows "[deleted]" because the account was deleted by the time of data collection. We removed these posts and comments in later analysis.
To answer the second research question, we selected and combined the top 50 members with the most posts, as well as the top 50 members with the most comments to generate a combined list of 83 accounts. These 83 members $(4.3 \%$ of all the identified accounts) created a substantial portion of the subreddit content, including 361 posts $(37.2 \%)$ and 2352 comments $(33.8 \%)$.

We conducted a content analysis of each member's contribution to the community to understand their role in the community using the constant comparative method [10]. During the open coding process, we grouped posts and comments under the authors. For each author, we looked for the following information in their generated content: whether and how they described their experience in the field of UX; what types of knowledge they brought to this community; and how they introduced such knowledge. Using open coding, we read each author's posts and comments to obtain an initial impression of their experience in UX and how they presented themselves in the communities, assigning a code (role) to each author. Researchers met several times to discuss emerging themes. We then consolidated these roles through axial coding. When there were multiple codes for one author, we selected a primary one based on the knowledge activities they engaged most frequently. We found that these top contributors can be generally categorized into five roles based on their primary contributions: knowledge broker, conversation facilitator, translator, experienced practitioner, and learner. In Section 5.2, we describe these five social roles in detail.

\section{Results}

\subsection{How does vocality influence knowledge activity in the online UX community?}

Table 1 includes descriptive statistics that represents threads' scores, number of comments, and author vocality (i.e., frequency of posts or comments). Note that by the time of data collection, there are negative scores only for comments because of API-related technical constraints.

Table 1. Descriptive statistics by frequency and score.

\begin{tabular}{|l|l|l|l|l|l|}
\hline & \multicolumn{2}{|l|}{ Post Information } & \multicolumn{2}{l|}{$\begin{array}{l}\text { Comment } \\
\text { Information }\end{array}$} \\
\hline & Score & $\begin{array}{l}\text { No. of } \\
\text { Comments }\end{array}$ & $\begin{array}{l}\text { Author } \\
\text { Vocality }\end{array}$ & Score & $\begin{array}{l}\text { Author } \\
\text { Vocality }\end{array}$ \\
\hline Min & 0 & 0 & 1 & -17 & 1 \\
\hline Max & 204 & 121 & 45 & 69 & 160 \\
\hline Avg. & 9.16 & 7.21 & 5.35 & 2.32 & 26.63 \\
\hline SD & 14.66 & 9.75 & 9.74 & 3.28 & 39.33 \\
\hline
\end{tabular}


In Table 1, a post's author vocality reflects the author's number of posts in the community. A comment's author vocality reflects the author's number of comments in the community. Both posts and comments have a wide range as indicated by the $\mathrm{min} / \mathrm{max}$ and SD (for both posts and comments) and the number of comments for posts given by the community. This phenomenon suggests that the online UX community values certain forms of knowledge production. However, vocal authors do not necessarily generate high-value posts, with a Pearson correlation coefficient of $\mathrm{r}=0.12$ between post score and author vocality $(n=961)$, and a Pearson correlation coefficient of $r=-0.11$ between number of comments and author vocality $(n=6835)$. Similarly, vocal comment givers do not always generate high-value comments, with a Pearson correlation coefficient of $\mathrm{r}=0.004$ between comment score and author vocality.

These findings suggest that the online UX community does not have a steady core of community members who define UX knowledge and practice through typical boundary management practices. Instead, many members who speak infrequently appear to be able to make contributions that are well received by the community. Consequently, knowledge production and diffusion does not follow the classic CoP model where knowledge is controlled and defined by core community members. Instead, knowledge generation is widely distributed across a variety of members.

We also found a mildly positive correlation between UX practitioners' number of posts and number of comments, with a Pearson correlation coefficient of $\mathrm{r}=0.28$. This suggests that people who are active in making posts are not necessarily active in making comments, and vice versa. Extreme examples, but not outliers, include a person who has made 45 posts but only 9 comments, and a person who has made 2 posts but 160 comments. Additionally, using the max score to measure UX practitioners' capacity of knowledge creation, we found no correlation between UX practitioners' max post score and max comment score, with a Pearson correlation coefficient of $r=0.04$. This indicates that people who are good at creating highvalue posts are not necessarily good at making highvalue comments. Extreme examples include a person who received a max post score of 204, but a max comment score of 4 , as well as a person who received a max post score of 0 , but a max comment score of 69 . These two correlation tests suggest that there may be distinct roles of community members who participated in knowledge activities in the community, with some being proficient at creating new topics to interest and engage the community, and others being more capable of giving informative comments.
Additionally, we also see posts and comments as a unified whole, representing how posters and commenters collaborated in knowledge activities. It is thus valuable to see the relationship between the value of posts and the value of comments. We measured the Pearson correlation coefficient between post score and number of comments $(\mathrm{r}=0.30)$, and max score $(\mathrm{r}=0.46)$ and average score $(\mathrm{r}=0.33)$ for comments. It is perhaps unsurprising that a higher-value post would attract more comments and that these comments were often judged to be of good value as well.

\subsection{What roles do community members take on when participating?}

Given the diversity in knowledge activities shown in the last subsection, we were interested in understanding the social roles that knowledge workers took on in this community.

\section{Knowledge Broker}

Knowledge brokers introduced knowledge they found novel and valuable to the community by sharing links to interesting UX articles, concepts, or newly published books. We found that $21.7 \% \quad(n=18 / 83)$ members fit into this category. They are characterized by frequently posting but rarely commenting. Here are the titles of five posts made by a knowledge broker:

Post 1: How Tools Have Shaped the Role of the Designer

Post 2: Dark Patterns are designed to trick you (and they're all over the Web)

Post 3: Seats in the street: How LA's outdoor furniture creates a more livable city

Post 4: 20 documentaries every designer should watch

Post 5: Four Themes for Successful Junior Designers

Each of the posts contained a link to an article discussing UX knowledge. The knowledge brokers shared links without adding any description. However, these posts did share some rhetorical similarities - using strong words to pique interest or curiosity. Knowledge brokers also shared knowledge when commenting on existing posts. For example, one commented:

Comment: They have a bunch of awesome points for why they aren't ideal.

The title is cheeky, but there is some really funny examples and valuable solutions. Nice solutions that work for both UX and developers, such as changing a two item dropdown to a radio button.

Check out some select alternatives:

* https://select2.github.io/examples.html

* https://twitter.github.io/typeahead.js/ 


\section{Translator}

Translators sought to bring academic knowledge into the community, drawing from their own experiences in other domains or disciplines. We only found $7.2 \% \quad(n=6 / 83)$ to be of this type. These participants tended to produce high-value posts and make a large number of comments. Translators are different from knowledge brokers who focused primarily on introducing practical UX knowledge. Here are examples of translating academic knowledge into the UX field:

Comment 1: UX architect and cultural anthropologist with several years of ethnographic field experience here. What /u/AnonymousUX and /u/Riimii both said are good points, so I'll add to those.

* **It's all data.** One of the advantages of ethnography is that it's like turning on a fire hose of data, both in terms of amount and kinds of data you can collect. Everything you see, hear, do, or say *is* the raw stuff of your data.

This is an instance where a member with academic training in anthropology sought to deepen the understanding of ethnography among UX practitioners.

This is my perspective as well. Human Factors and ergonomics as disciplines have different histories, assumptions, and foci than UX (see chapter 2 in Ritter et al's Foundations for Designing User-Centered Systems). User-centered or human-centered design is a broader approach that encompasses digital and physical activities, contexts, etc, like what /u/poorfitponcho said.

Comment 2: Author has a lot of opinion and seems to have set up his Slack poorly but...He does raise several very common [CSCW](https://en.wikipedia.org/wiki/Computersupported_cooperative_work) issues which are in fact present in many collaboration systems like Slack that Slack has also not resolved yet...

Comment 3: Not really a thing of the past. Human Factors is very much still a thing. There are still dozens of schools that have [Human Factors](http://psychology.gmu.edu/programs/la-mapsyc-hf) degree [programs](https://www.hfes.org/web/Students/grad_p rograms.html) and the field has well regarded journals [example 1](http://hfs.sagepub.com/), [example 2](http://www.hfes.org/publications/) These programs tend to be more common in psych departments now, but there are still programs in [Human Factors Engineering](http://isd.engin.umich.edu/professionalprograms/human-factors-engineering/index.htm)

\section{Experienced Practitioner}

Experienced practitioners often self-identified in their posts or comments as a senior UX practitioner with years of experience in UX design, including expertise in working with diverse groups and demonstrated familiarity with the UX industry. $22.9 \%(n=19 / 83)$ of top users belonged to this category. Their contribution was characterized by lengthy posts and frequent comments, and they usually shared their understandings of the UX profession in a definitive, authoritative tone.

Comment: I have various documents I've types up on conducting research (e.g. best practice or industry specific), from carrying out stakeholder interviews to researching users needs. Also plenty on how to carry out heuristic reviews, SEO audits, routes in/out, topographic reviews, strategy process etc.

Also I have justification of these - why they're done, what the out puts are, what you can do with the results.

A lot of it is stripped from places like this http://www.servicedesigntools.org/repository - then I tailor them for my needs (also UX pin has a few bits too). Once you've done a task analysis for one mobile banking app - you can be sure there's commonalities within that sector, so a lot of stuff is reusable.

\section{Conversation Facilitator}

Unlike the former three types of community members, conversation facilitators did not introduce new knowledge. They tended to start and maintain thoughtful conversations with others, with their posts frequently receiving high numbers of comments. We found $20.5 \%(n=17 / 83)$ to be conversation facilitators. They often started conversations by referring to a common product that many people could have an opinion on. Here are the titles of a few example posts:

Post 1: Looking for examples of US state selectors where the user can select multiple US states.

Post 2: Anyone else think Pokémon Go is a hot mess?

Post 3: Online daters out there: Tinder, Bumble, or Mingle UX?

When making comments, conversation facilitators applied rhetorical strategies that could facilitate further discussions, such as asking for more information and brainstorming scenarios.

Comment: Maybe add a twist to it and make it your own instead of copying 100\%. That's what I usually do if I REALLLY like a design.

\section{Learner}

Learners were generally students or junior UX designers who relied upon the community for suggestions and advice. We identified 27.7\% $(n=23 / 83)$ of top users that fit into this category. Learners often made posts but their posts were rated relatively low in comparison to the average. Here are two examples of their posts:

Post 1: how specific does a portfolio have to be? 
Post 2: Is it legal to use other people style on your project

They often self-identified as newcomers and spoke with a modest, grateful attitude, reflecting a sense of camaraderie with the UX community while also anticipating the responses of those with more expertise.

Comment: thanks man :)

$i$ did two software engineering internships and halfway through the first one $i$ decided it just wasn't for me. $i$ wanted a career in something that would have a bigger impact on people. debated psychiatry or therapy but wasn't very eager about the pay cut i'd be getting. discovered ux halfway through my second internship, my last internship was full ux:)

\section{Discussion}

We have analyzed the relationship between UX practitioners and their knowledge-building communication in an online UX community. Our study confirmed previous research findings that UX knowledge is still developing and the disciplinary identity of UX practitioners is still underdetermined [21]. We contribute to the literature on roles in online communities by demonstrating how discursive activities have distinct qualities that can be used to identify social roles that are not explicitly predefined by platform designers. Rather, the emergence and development of these social roles are closely related to the nature of this particular online community's focus on an emerging occupation with volatile disciplinary boundaries. Next, we will detail these social roles in the context of UX as an emerging occupation.

The five roles of knowledge workers that we identified represent one productive way of characterizing the movement of knowledge in and around the UX community, reflecting an ongoing divide between the pragmatic expectations of knowledge in UX practice, and the role of translators in identifying abstract, academically-defined theories and concepts and making them relevant for the practitioner community. This movement reflects the "trickle-down" of knowledge in HCI, as defined by Gray, Stolterman, and Siegel [24], yet in this community, we see no parallel "bubbling-up" of knowledge back into the academic discourse.

Figure 1 illustrates the relationship of the various identified roles to knowledge production and the research/practice divide. As shown in the figure, each role is indispensable, even if the statistical representation of these interactions as they relate to posts or comments may appear less significant. The UX field is continuously absorbing knowledge from outside the community, facilitated by the work of members in the experienced practitioner, translator, and knowledge broker roles. Given the inter- and trans-disciplinary nature of UX, it is easy to see how learning and identity in this subreddit manifested these synthetic and fusionoriented qualities, rather than moves to define and defend disciplinary boundaries. We observed many activities of borrowing knowledge from other domains as first characterized by Klein [31]. Knowledge brokers repeatedly introduced knowledge from multiple

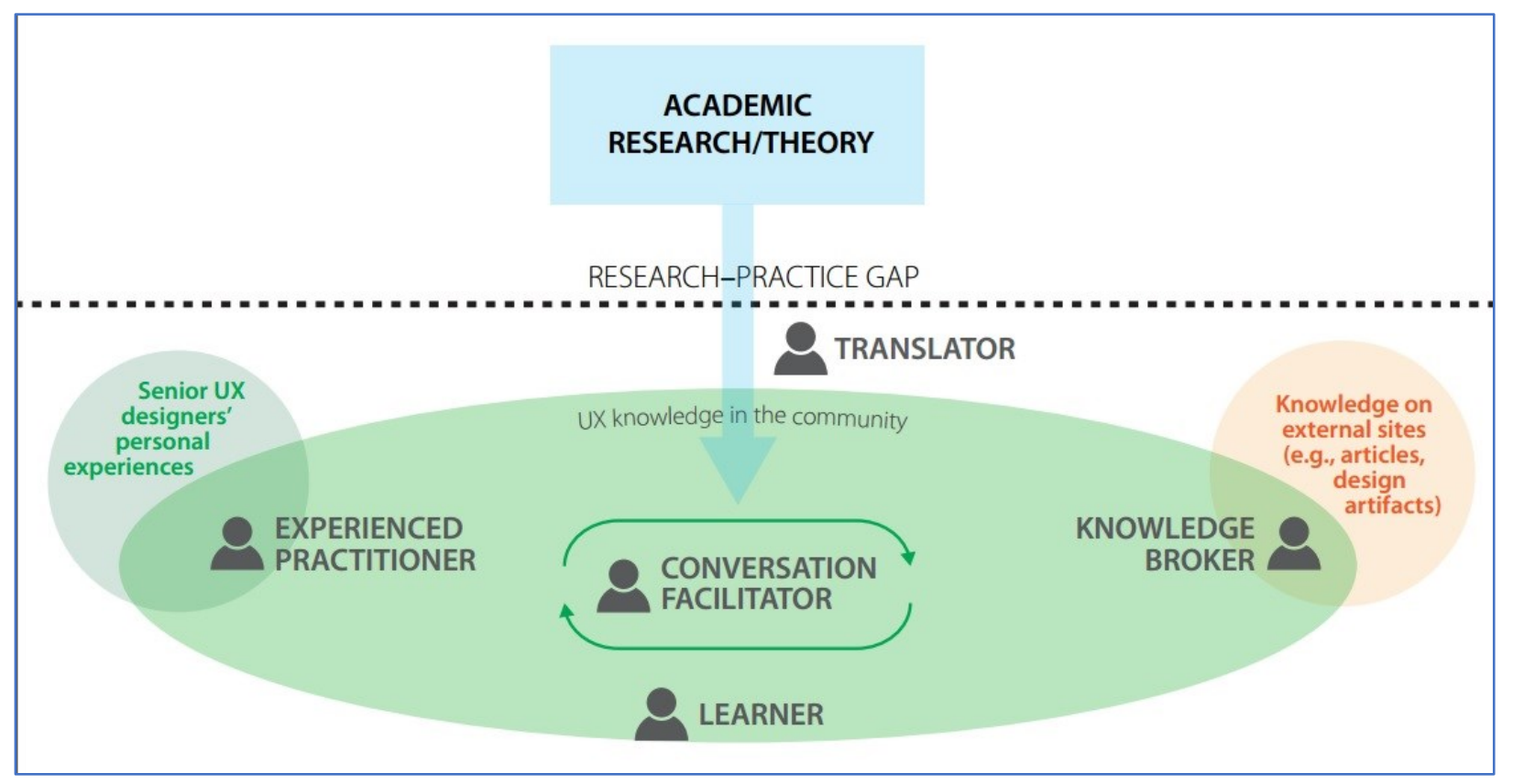

Figure 1. Social Roles in the UX Community. 
external websites, reflecting the diverse nature and source of UX knowledge which is not restricted by academic reification or interpretation of the field [23]. Translators identified and introduced concepts and theories from various academic disciplines such as anthropology, psychology, and computer science, reflecting the traditional disciplinary origins of UX. Conversation facilitators may appear to have a minimal impact based on the lack of highly popular posts or comments, but these members contributed to the movement of knowledge inside the community, increasing the duration of conversations and the number of interlocutors engaged in these conversations. Learners, often with background in another domain, showed their desire to learn from other fields, taking on what could be considered a "newcomer" role in the parlance of CoP. Learners may not have much new knowledge to offer, but were important in sustaining the population of the community, showing promise in developing towards the other roles. One might argue that learners do perform some form of legitimate peripheral participation in comprehending the community norms and gaining experience in making posts and comments with higher value, thus externalizing the norms and values of the UX community and bringing tacit understandings of disciplinary identity to the foreground of conversation. Such development appears to be primarily focused on communicative practices that enable community involvement, not UX knowledge itself.

\subsection{Practice-led research on UX}

Scholarship regarding the nature of design practice, known as practice-led research, has been proposed as one means of documenting and explicating the tacit knowledge required to engage in design activity [41]. The roles that we identified in this community appear to be important to the ongoing discourse regarding UX practice in the human-computer intereaction academic community, serving as one example of practice-led research in online spaces.

The knowledge activities in this community indicate a much more fragmented, yet supportive, means of engaging with the complexity of UX practice as compared to other established professions or even academic definitions of UX. The experienced practitioner and knowledge broker roles, in particular, show promise in identifying appropriate and generative areas for knowledge exchange that have value to the burgeoning yet nascent notion of UX. These exchanges indicate a discursive formation of the boundaries around and definition of UX, and the legitimating of various voices, types of knowledge, and disciplinary voices that appear to have resonance for this community.
A practice-led understanding of UX knowledge and disciplinarity may point to communities such as this subreddit as a vital mechanism for ongoing professionalization. What is currently unclear is how these communities may be productively viewed and supported from the perspective of academia or formal scholarship; while the trickle-down of knowledge from academia does represent one type of knowledge dissemination and discussion in this community (via the translator role), there appears to be no corresponding "bubbling up" of UX practitioner knowledge into the academic discourse. Addressing this unidirectional knowledge flow may be critical to ensuring the longterm alignment of the education of future UX designers and the evolving UX practice community.

\subsection{Supporting a community of emerging occupation}

We claim that a community of emerging occupation is a type of community of practice that exhibits ongoing construction of disciplinary knowledge towards the goal of professionalization of the occupation. While many communities of practice exist that are focused on various subject matters, such as eSports [9] and handicraft [37], show the tendency of professionalization, a community of emerging occupation such as the UX community documented in this study appears to have distinctive external forces that lead to different outcomes. In the community under study, the UX occupation's sustained high job demands [12] as well as the nascent UX programs at the undergraduate level in a few universities $[2,17]$ form not only a community of interest that is linked to an evolving occupation, but also a space where the ideology and breadth of those interests are open for debate and change.

Communities of emerging occupation as a type of online community structure may allow for greater discussion regarding the external and internal forces that cause a community to form and be sustained over time. In regard to UX, these communities may play a critical role in bridging the knowledge gap between the rapid growing UX industry and the nascent landscape of UX degree programs and certifications. However, Reddit as a general-purpose online community does not include specific considerations for supporting this particular form of community that is concerned with knowledge production. For example, there is no explicit design support for defining the five social roles, but clearly community members have appropriated the sociotechnical features of Reddit for their own knowledge activities. Future design of socio-technical systems might consider mechanisms that can support categorizing these different roles and activities to 
facilitate the production, archival, and circulation of disciplinary knowledge. More research is also needed to further document the unique features of communities of emerging occupation, describing salient interactions and actors, while also bubbling up the knowledge generated by practitioners.

\subsection{Implications for design and UX pedagogy}

The interactions within this design-focused online community reveal ongoing patterns of learning that exist beyond the design classroom or single workplace. Interactions among learners and members taking on other roles reveals the lack of formal education structures or informal means of licensure or certification that has universal recognition. This reveals the nascent nature of UX professional identity, and the corresponding lack of educational standards to train students to succeed in this field. It appears that the online community under study to some extent fills the gap in UX knowledge production and dissemination by bringing people with diverse background, experiences, and seniority together. Thus, the knowledge worker roles revealed in this community is informative for design and UX pedagogy, increasing our collective understanding of how professionalization and the development of competence in design might be productively studied and understood beyond the formal educational context.

We believe that these community interactions may reveal two primary areas of value for design education and scholarship. First, these community interactions demonstrate the mechanisms by which design professionalization is occurring, highlighting the identification of a coherent body of UX knowledge by practitioners. This knowledge building is practitionerdriven, motivated by pragmatism and the needs of practice rather than the demands of an accrediting or certification body. Future research may allow for greater alignment of industry demands and formal educational programs, perhaps minimizing the research-practice gap as it relates to formal academic preparation. Second, the roles that UX practitioners take on in this space operationalize the constant desire and need for the development of individual and disciplinary competence. While patterns of learning in the design studio are relatively well understood, the ongoing management of competence by individual practitioners is still largely understudied and, as a consequence, not well understood. Online communities such as this subreddit allow unique access into the development of competence, including aspects of lifelong learning that would be valuable for educators to scaffold in traditional educational environments.

\section{Conclusion}

We have shown the nuanced relationship between UX knowledge production and the circulation of this knowledge via various knowledge worker roles in an online UX community. The distinct roles that community members take on in online knowledge activities allows substantial insight in understanding how learning occurs beyond the traditional design classroom, and the role that knowledge-sharing interactions may play in allowing practitioners to maintain both individual and disciplinary competency over time.

\section{References}

[1] Alexa. How popular is reddit.com? 2017. http://www.alexa.com/siteinfo/reddit.com.

[2] Allison, N. UX activity in UK Higher Ed web teams. usability ed, 2014. http://usability-

ed.blogspot.co.uk/2014/07/ux-activity-in-uk-higher-ed-webteams.html.

[3] Arazy, O., Ortega, F., Nov, O., Yeo, L., and Balila, A. Functional Roles and Career Paths in Wikipedia.

Proceedings of the 18th ACM Conference on Computer Supported Cooperative Work \& Social Computing CSCW '15, ACM Press (2015), 1092-1105.

[4] Blevis, E., Chow, K., Koskinen, I., Poggenpohl, S., and Tsin, C. Billions of interaction designers. interactions 21, 6 (2014), 34-41.

[5] Brown, R. Group processes: Dynamics within and between groups. Wiley-Blackwell, 1988.

[6] Buchanan, R. Rhetoric, humanism, and design. In Discovering design: Explorations in design studies. University of Chicago Press, 1995, 23-66.

[7] Buntain, C. and Golbeck, J. Identifying social roles in reddit using network structure. Proceedings of the $23 \mathrm{rd}$ International Conference on World Wide Web - WWW' 14 Companion, ACM Press (2014), 615-620.

[8] Bureau of Labor Statistics. Occupational employment statistics, 1994. U.S. Dept. of Labor, Bureau of Labor Statistics, 1996.

[9] Carter, M. and Gibbs, M.R. eSports in EVE Online: Skullduggery, Fair Play and Acceptability in an Unbounded Competition. FDG, (2013), 47-54.

[10] Corbin, J. and Strauss, A. Basics of Qualitative Research: Techniques and Procedures for Developing Grounded Theory. SAGE Publications, 2007.

[11] Danyel Fisher, Marc Smith, and Howard T. Welser. You Are Who You Talk To: Detecting Roles in Usenet

Newsgroups. HICSS'06, IEEE (2006), 1-10.

[12] Eugenios, J., Fox, E.J., Hargreaves, S., and Vasel, K. Best Jobs in America: CNNMoney/PayScale's top 100 careers with big growth, great pay and satisfying work. $C N N$ Money, 2015.

http://money.cnn.com/gallery/pf/2015/01/27/best-jobs2015/index.html. 
[13] Fabricant, R. Scaling Your UX Strategy. Harvard Business Review, 2013. https://hbr.org/2013/01/scaling-yourux-strategy.

[14] Forlizzi, J. and Battarbee, K. Understanding experience in interactive systems. DIS '04, ACM Press (2004), 261-268. [15] Forte, A., Larco, V., and Bruckman, A. Decentralization in Wikipedia Governance. J. Manage. Inf. Syst. 26, 1 (2009), 49-72.

[16] Füller, J., Hutter, K., Hautz, J., and Matzler, K. User Roles and Contributions in Innovation-Contest Communities. Journal of Management Information Systems 31, 1 (2014), 273-308.

[17] Getto, G. and Beecher, F. Toward a Model of UX Education: Training UX Designers Within the Academy. IEEE Transactions on Professional Communication 59, 2 (2016), 153-164.

[18] Gliwa, B., Zygmunt, A., and Koźlak, J. Analysis of Roles and Groups in Blogosphere. In Springer, Heidelberg, 2013, 299-308.

[19] Goffman, E. The presentation of self in everyday life. Peter Smith Pub, Inc, 1999.

[20] Gordon, E.E. Winning the global talent showdown : how businesses and communities can partner to rebuild the jobs pipeline. Berrett-Koehler Publishers, 2009.

[21] Gray, C.M. "It's More of a Mindset Than a Method":

UX Practitioners' Conception of Design Methods. CHI '16, ACM Press (2016), 4044-4055.

[22] Gray, C.M. and Howard, C.D. Designerly Talk in NonPedagogical Social Spaces. Journal of Learning Design 7, 1 (2014), 40-58.

[23] Gray, C.M. and Kou, Y. UX Practitioners' Engagement with Intermediate-Level Knowledge. DIS '17 Companion, ACM Press (2017), 13-17.

[24] Gray, C.M., Stolterman, E., and Siegel, M.A.

Reprioritizing the relationship between HCI research and practice: bubble-up and trickle-down. DIS '14, ACM Press (2014), 725-734.

[25] Gray, C.M., Toombs, A.L., and Gross, S. Flow of Competence in UX Design Practice. CHI' 15, ACM Press (2015), 3285-3294.

[26] Hart Research Associates. Falling Short? College Learning and Career Success. 2015.

[27] Hassenzahl, M. and Tractinsky, N. User experience - a research agenda. Behaviour \& Information Technology 25, 2 (2006), 91-97.

[28] Herrmann, T., Jahnke, I., and Loser, K.-U. The Role Concept as a Basis for Designing Community Systems. In F. Darses, ed., Cooperative Systems Design: Scenario-based Design of Collaborative Systems. IOS Press, 2004, 163-178. [29] Hessel, J., Tan, C., and Lee, L. Science, AskScience, and BadScience: On the Coexistence of Highly Related Communities. ICWSM, (2016).

[30] Jensen-Inman, L. Why is there an increase in demand for UX designers? Center Centre, 2013.

$\mathrm{http} / / /$ centercentre.com/blog/2013-12-19-why-is-there-anincrease-in-demand-for-ux-designers.
[31] Klein, J.T. Interdisciplinarity : history, theory, and practice. Wayne State University Press, 1990.

[32] Lave, J. and Wenger, E. Situated Learning: Legitimate Peripheral Participation. Cambridge University Press, 1991. [33] Law, E.L.-C., Roto, V., Hassenzahl, M., Vermeeren, A.P.O.S., and Kort, J. CHI 09, ACM Press (2009), 719-728. [34] Marlow, J. and Dabbish, L. From rookie to all-star: professional development in a graphic design social networking site. $C S C W^{\prime}$ '14, ACM Press (2014), 922-933. [35] Merisotis, L. America's Talent Gap: Five Areas of Focus. huffingtonpost, 2016. http://www.huffingtonpost.com/jamie-merisotis/americastalent-gap-five- b 9821556.html.

[36] Mills, R.A. and A., R. Reddit.com: A census of subreddits. Proceedings of the ACM Web Science Conference on ZZZ - WebSci '15, ACM Press (2015), 1-2.

[37] Pace, T., O’Donnell, K., DeWitt, N., Bardzell, S., and Bardzell, J. From organizational to community creativity: paragon leadership \& creativity stories at etsy. $C S C W$ '13, ACM Press (2013), 1023-1034.

[38] Pfeil, U., Svangstu, K., Ang, C.S., and Zaphiris, P. Social Roles in an Online Support Community for Older People. International Journal of Human-Computer Interaction 27, 4 (2011), 323-347.

[39] Schein, E.H. Occupational socialization in the professions: the case of role innovation. Journal of psychiatric research 8, 3 (1971), 521-30.

[40] Siddiqui, J.A., Allendoerfer, C., Adams, R.S., and Williams, B. Integration of Scholarship: Interconnections among Three Studies on Becoming an Engineering Education Researcher. International Journal of Engineering Education 32, 6 (2016), 2352-2377.

[41] Star, S. and Griesemer, J. Institutional Ecology, 'Translations' and Boundary Objects: Amateurs and Professionals in Berkeley's Museum of Vertebrate Zoology, 1907-39. Social Studies of Science 19, 3 (1989), 387-420.

[42] Stolterman, E. The Nature of Design Practice and Implications for Interaction Design Research. International Journal of Design 2, 1 (2008), 55-65.

[43] de Vries, S. Online knowledge communities: meeting places for continuing professional development. In Informatics and the Digital Society. Springer US, Boston, MA, 2003, 215-224.

[44] Vygotsky, L.S. Thought and language. MIT Press, 2012. [45] Welser, H.T., Cosley, D., Kossinets, G., et al. Finding social roles in Wikipedia. Proceedings of the 2011 iConference on - iConference '11, ACM Press (2011), 122129.

[46] Wenger, E. Communities of Practice: Learning, Meaning, and Identity. Cambridge University Press, 1999. [47] World Economic Forum. The future of jobs: Employment, skills and workforce strategy for the fourth industrial revolution. Geneva, Switzerland, 2016. 